\title{
Topical Therapeutic Options in Corneal Neuropathic Pain
}

\author{
Jeremy Nortey ${ }^{1,2}$, David Smith ${ }^{3}$, Gerami D. Seitzman ${ }^{2,4}$ and John A. Gonzales ${ }^{2,4 *}$ \\ ${ }^{1}$ School of Medicine, University of North Carolina, Chapel Hill, NC, United Statesa, ${ }^{2}$ Francis I. Proctor Foundation, University of \\ California, San Francisco, San Francisco, CA, United States, ${ }^{3}$ A\&O Compounding Pharmacy, Vallejo, CA, United States, \\ ${ }^{4}$ Department of Ophthalmology, University of California, San Francisco, San Francisco, CA, United States
}

Purpose of Review: Corneal neuropathic pain can be difficult to treat, particularly due to its lack of response to standard dry eye therapies. We describe a variety of topical therapeutic options that are available to treat corneal neuropathic pain with a significant or primary peripheral component. We also describe possible mechanisms of action for such topical therapies.

Recent Findings: Topical corticosteroids and blood-derived tear preparations can be helpful. Newer therapies, including topical lacosamide and low-dose naltrexone are emerging therapeutic options that may also be considered.

Summary: Corneal neuropathic pain with a significant peripheral component may be managed with a variety of topical therapeutic options.

OPEN ACCESS

Edited by:

Dario Rusciano,

Sooft Italia SpA, Italy

Reviewed by:

Piera Versura,

University of Bologna, Italy

Anna Maria Roszkowska,

University of Messina, Italy

*Correspondence:

John A. Gonzales

john.gonzales@ucsf.edu

Specialty section:

This article was submitted to

Neuropharmacology,

a section of the journal

Frontiers in Pharmacology

Received: 02 September 2021

Accepted: 28 December 2021

Published: 31 January 2022

Citation:

Nortey J, Smith D, Seitzman GD and Gonzales JA (2022) Topical Therapeutic Options in Corneal Neuropathic Pain.

Front. Pharmacol. 12:769909. doi: 10.3389/fphar.2021.769909
Keywords: corneal neuropathic pain, neuropathic ocular pain, low-dose naltrexone, lacosamide, sub-basal corneal nerve plexus, serum tears

\section{INTRODUCTION}

Corneal neuropathic pain has perplexed ophthalmologists particularly because of its symptomatic masquerade as dry eye disease. Indeed, some patients with corneal neuropathic pain may have dry eye findings that are compatible with evaporative and/or aqueous deficient dry eye disease. However, these patients fail to respond to dry eye treatments (Galor et al., 2015a; Galor et al., 2016). Some patients may even be suspected of malingering or of having somatic symptom disorders. Patients often have seen a variety of ophthalmologists for second, third, or more opinions. While corneal neuropathic pain can certainly exist in the setting of aqueous sufficient and deficient dry eye, the common clinical situation encountered is a relatively unremarkable ocular surface examination in a person complaining of significant ocular discomfort (the so-called "pain without stain" patient) (Rosenthal et al., 2009). Increasing awareness of the existence of corneal neuropathic pain, a distinct clinical entity from aqueous sufficient and aqueous deficient dry eye disease, can benefit patients by advancing them on a more directed course to more specifically addresses their discomfort (Craig et al., 2017). Management of neuropathic pain, however, continues to be a challenge, in part, due to a lack of comparative clinical trials identifying the most effective treatment strategies. Often, determining whether there is a primarily peripheral or a primarily central component of neuropathic pain (or perhaps, mixed) can identify routes of therapy that may be most efficiacious (Rosenthal et al., 2009; Rosenthal and Borsook, 2012; White et al., 2014; Dieckmann et al., 2017; Ozen et al., 2017). In patients exhibiting a significant peripheral component of corneal neuropathic pain or discomfort, topical therapeutic approaches may be of benefit (Asbell, 2006; Mondy et al., 2015; Chen et al., 2019; Siedlecki et al., 2020). This paper will use both the terms "pain" and "discomfort" to describe the subjective complaints of patients suffering from corneal 
TABLE 1 | Topical therapeutic options available as eye drops for peripheral corneal neuropathic pain.

Topical therapies

Corticosteroids

Blood-derived tear preparations

Lacosamide

Low-dose naltrexone

Enkephalin modulators

\section{Mechanism of action}

Anti-inflammatory properties can decrease the density of dendritic cells

Autologous or allogenic tear promote corneal epithelial cell health and are associated with fewer features of neuropathy of sub-basal nerve plexus

Amino acid molecule that decreases hyperexcitability of corneal cold-sensitive nerve terminals

Opioid antagonist known for its effects on bodily neuropathic pain

A relatively new therapy that acts as a neuropeptide inhibitor with effects on modulating pain neuropathic pain. Some patients point out that they do not experience "pain" per se, but rather a sensation that is often difficult to define but is, nevertheless, uncomfortable.

The nerves within the cornea stem from branches of the nasociliary nerve which itself is a branch of the ophthalmic division of the trigeminal nerve also known as the first division of the fifth cranial nerve. Nasociliary nerve branches enter the peripheral cornea radially before traveling anteriorly to penetrate Bowman's layer and forming the sub-basal nerve plexus. Ocular surface pain and corneal neuropathic pain is initiated by these peripheral nerves and their free endings located within the cornea (Mehra et al., 2020). Other pain nerve fibers, called nociceptor fibers, variably respond to different stimuli. Mechanoreceptors are responsible for the sharp pain that is felt upon mechanical stimulation such as an object coming in contact with the cornea. Polymodal receptors respond to mechanical, thermal, $\mathrm{pH}$, and chemical changes within the environment, and are associated with burning and stinging pains. Cold thermoreceptors respond to changes in temperature and tear osmolarity, and can be associated with ocular surface discomfort that may be generated with evaporative tear (Rosenthal and Borsook, 2012; Cho et al., 2019; Mehra et al., 2020). Because of its peripheral location in the cornea, the subbasal nerve plexus is the peripheral-most component to efferent and afferent corneal neuropathic pain. However, there is also a significant central component to corneal neuropathic pain, which involves first- and second-order nerve input to the thalamus and, ultimately, the cortex with additional modulation from the thalamus and amygdala (Rosenthal and Borsook, 2012; Mehra et al., 2020).

Our group at the Proctor Foundation at the University of California San Francisco serves as a major tertiary center for the evaluation and management of patients with corneal neuropathic pain. Herein, we discuss the topical (eye drop) therapeutic options that are suggested for patients with a component of peripheral corneal neuropathic pain. Our experience has been that patients with peripheral corneal neuropathic pain are very motivated to understand what eye drop therapies may be of potential benefit to them. While there are a variety of eye drops that can be used in corneal neuropathic pain, no randomized controlled trials comparing one class of eye drop to another in corneal neuropathic pain currently exists. Commercially available and compounding pharmacy-only available drops are reviewed. To ensure a comprehensive review, we searched for topical (eye drop) therapeutics in PubMed using search terms, "neuropathic pain", "ocular pain", and "eye pain" and evaluated the results if the abstracts described topical therapeutics. A total of 204 records were screened and 182 records were excluded. Of the 22 reports assessed for eligibility, additional records were excluded due to focusing on post-operative treatments (4), focusing on systemic treatments (2), and a lack of relation to neuropathiic ocular pain (6). Ten studies were included in this review. Our group's experience in topical therapy was also included (Table 1).

\section{ASSESSMENT OF CORNEAL NEUROPATHIC PAIN}

The assessment of corneal neuropathic pain involves 1) identifying the presence of subjective ocular pain and, if possible, 2) identifying features that align with a neuropathic phenotype. Questionnaires and in vivo confocal microscopy can be helpful in distinguishing patients with corneal neuropathic pain from those with non-neuropathic ocular discomfort that can be associated with dry eye disease. Patients may have features of both an aqueous sufficient or aqueous deficient dry eye disease in addition to frank corneal neuropathic pain.

Questionnaires that are specific for ocular pain can be easily self-administered in the clinical setting or administered by staff and include the Ocular Pain Assessment Survey (OPAS) and the Neuropathic Pain Symptom Inventory modified for ocular pain (NPSI-Eye) (Qazi et al., 2016; Farhangi et al., 2019).

Prior to 2016, there was no standardized and validated way of assessing ocular pain intensity and aggravating factors. The OPAS was a major step forward in identifying, anatomically locating and quantifying the intensity ocular pain. Comprised of 27 questions, spanning a gold-standard visual analog system of quantifying pain intensity (Wong-Baker FACES pain rating scale), aggravating factors, and quality of life features, the OPAS is not only comprehensive but useful in monitoring response to therapy (Qazi et al., 2016). The NPSI attempts to identify neuropathic-specific ocular pain symptoms, including burning sensation (Bouhassira et al., 2004; Farhangi et al., 2019). The identification of specific neuropathic pain features is important because such patients may be less apt to respond to artificial tears, which may be helpful in patients with nonneuropathic ocular discomfort (Galor et al., 2015b).

Following questionnaires, a critical component of the clinical examination is determining a patient's subjective response to topical anesthetic. Complete improvement in discomfort or pain is in keeping with a primarily peripheral corneal neuropathic pain process. If some component of discomfort persists, this may 
suggest that there is a component of the pain that is central while a complete lack of response to topical anesthetic suggests that the discomfort is primarily central. For those corneal pain processes that have at least some component of a peripheral phenotype, topical pain modulatory therapies may be of benefit. Herein, we discuss a variety of topical therapeutic options that are available to clinicians for managing peripheral corneal neuropathic pain.

\section{Topical Corticosteroids}

In both dry eye disease and neuropathic ocular pain, inflammatory cells may mediate a component of the discomfort experienced by patients. Antigen-presenting cells, including dendritic cells, can be found within the corneal epithelium and stroma, and are important players in the complex immune functions and responses exhibited by the cornea in both processes (Hamrah et al., 2003). Compared to control patients, in vivo corneal confocal microscopy demonstrates a higher density of dendritic cells in patients with dry eye and corneal neuropathic pain (Kheirkhah et al., 2015; Shetty et al., 2016a; Nicolle et al., 2018). Moreover, in some cases, particularly in aqueous deficient dry eye disease, dendritic cells may be larger and be composed of more individual dendrites than in aqueous sufficient dry eye disease (Kheirkhah et al., 2015). Nicolle et al. (2018) To counterbalance this, endogenous peptides, known as enkephalins, serve to mitigate pain. Moreover, notable effects on in vivo confocal microscopy show a decrease in density of dendritic cells after treatment (Villani et al., 2015). Dendritic cells may express inflammatory cytokines and enzymes that degrade neuropeptides, thereby augmenting corneal nociceptors which are involved in initiating the perception of pain (Shetty et al., 2016a; Shetty et al., 2016b; Khamar et al., 2019). Indeed, it is hypothesized that dendritic cell signaling may be involved in mediating and enhancing nociceptive properties in a variety of dry eye, corneal neuropathic pain, and systemic neuropathy diseases and syndromes (Klitsch et al., 2020). Animal models of dry eye disease have demonstrated that dendritic cells can secrete a variety of proteins that activate downstream chemokines and cytokines that can modulate inflammation on the ocular surface (Gandhi et al., 2013; Zhang et al., 2014). Topical corticosteroids have well known anti-inflammatory effects. Thus, decreasing the density of dendritic cells with topical corticosteroids is one approach that may help in cases of corneal neuropathic pain where confocal microscopy identification of sub-basal dendritic cells is a predominant feature (Villani et al., 2015).

\section{Blood-Derived Tear Preparations}

Blood-derived tear preparations contain various growth factors, vitamins, and cytokines and could be considered more similar to natural tears than commercially available over-the-counter artificial tear products. Such tear preparations can be derived from a patient's own serum as autologous serum tears, from platelet rich plasma, or from allogeneic sources, such as donor cord blood (Tsubota et al., 1999a; Wu et al., 2021). Serum has been shown to promote the differentiation of corneal and conjunctival epithelial cells to express mucins (Gipson et al., 2003). This allows for the migration of corneal epithelial cells in a dose-dependent fashion and may, in part promote corneal epithelial health by stimulating expression of other growth factors and receptors (Phan et al., 1987; Tsubota et al., 1999a; Tsubota et al., 1999b; Geerling et al., 2001). A healthy corneal epithelium helps protect the sub-basal nerve plexus.

There has been some debate about the efficacy of autologous serum tears for dry eye disease. An extensive review by the Cochrane Database Group to identify randomized controlled trials evaluating the efficacy of autologous serum tears compared to artificial tears did not find significant evidence of a long-term durable benefit of autologous serum tears (Pan et al., 2017; Aggarwal et al., 2019). However, some studies have found in pain associated with dry eye, cord blood is superior to placebo (Campos et al., 2020). In non-randomized, observational series, platelet rich plasma drops helped to alleviate pain in corneal surgery-related corneal trauma (Alio et al., 2018).

Neuropathic ocular pain, which is distinctly different from aqueous deficient or sufficient dry eye disease, may benefit from blood-derived tear preparations that studies of general dry eye disease have not been powered to detect. Indeed, in patients with dry eye disease, serum tears have been shown to decrease basal epithelial cell density on confocal microscopy (Mahelkova et al., 2017). While some studies using serum tears in dry eye disease did not identify significant changes in the number of Langerhans cells or activated keratocytes or in the features of the sub-basal nerve plexus, other studies found that corneal nerve morphology improved with fewer neuropathic features using blood-derived tear products (Giannaccare et al., 2017; Mahelkova et al., 2017). The average concentration of serum growth factors vary according to patients who suffer from numerous systemic disease as comparted to healthy subjects with only ocular surface disease. This may be one reason explaining some therapeutic variability of serum tears in different patient populations (Ripa et al., 2020; Siedlecki et al., 2020).

In corneal neuropathic pain, serum tears have been described to be helpful in patients experiencing discomfort to light (photoallodynia) (Aggarwal et al., 2015). Autologous serum has been shown to decrease findings of sub-basal corneal nerve beading and neuromas (Aggarwal et al., 2015). In addition, serum tears have been associated with an improvement in other nerve metrics (as assessed by semiautomated quantification by ImageJ analysis) including total nerve length, nerve number, decrease in nerve reflectivity, and decrease in nerve tortuosity (Aggarwal et al., 2019). Such improvements in nerve metrics have also been correlated with an improvement in ocular pain by patients, suggesting that the resolution of neuropathic features is associated with an improvement in corneal nerve function (Aggarwal et al., 2019). Fresh frozen plasma and platelet-enriched plasma have similar purported benefits as serum tears and are worthy of future inverstigation with regard to ocular neuropathic discomfort/pain (Wang et al., 2021).

\section{Topical Lacosamide}

Lacosamide $\left(\mathrm{C}_{13} \mathrm{H}_{18} \mathrm{~N}_{2} \mathrm{O}_{3}\right.$, molecular weight $250.29 \mathrm{~g} / \mathrm{mol}$, pubchem.ncibi.hlm.nih.gov accessed August 1, 2021) is an amino acid molecule that was originally developed as an 
antiepileptic medication. Its main mechanism of action is to selectively enhance the slow inactivation (as opposed to the fast inactivation) of voltage-gated sodium channels (Errington et al., 2008; Niespodziany et al., 2013; Rogawski et al., 2015). Lacosamide also binds with the collapsin-response mediator protein-2 (CRMP-2), involved in modulating neurite outgrowth, which is important in establishing new neuronal projections in developing neurons as well as in regenerating nerves (Wilson and Khanna, 2015; Wang et al., 2018).

While corneal pain is sensed by mechano-nociceptors and polymodal nociceptors, cold thermoreceptors also play a role in the perception of ocular pain and discomfort (Belmonte and Gallar, 2011). Modulation of cold thermoreceptors, then, has been a potential therapeutic target. Topical lacosamide, in an ex vivo model, has been shown to decrease the hyperexcitability of corneal cold-sensitive nerve terminals (Kovács et al., 2016). In an aqueous deficient animal model (in which the lacrimal glands had been extirpated), the hyperexcitability as measured by the nerve terminal impulses in corneal cold-sensitive nerve terminals was decreased (Kovács et al., 2016).

Lacosamide $1 \%$ is produced from preservative-free Vimpat (UCB Inc., Smyrna, Georgia) $10 \mathrm{mg} / \mathrm{ml} 20 \mathrm{ml}$ vial. It is important to note that Vimpat is a Schedule 5 drug and all state and federal laws and regulations regarding controlled substances must be followed when prescribing and dispensing this drug. The compounding of lacosamide $10 \mathrm{mg} / \mathrm{ml}$ is an aseptic transfer from the injection vial to the droptainers or dispensing devices. When assigning a beyond use date, pharmacies must follow corresponding state and United States Pharamcopeia (USP) General Chapter 797 regulations. According to USP General Chapter 797, a beyond use date of 14 days refrigerated may be assigned. The package insert for Vimpat states that it is not to be frozen. The product Vimpat $20 \mathrm{mg} / 20 \mathrm{ml}$ is available through drug wholesalers only as packs of 10 . It is important to find a pharmacy that is willing to make the initial investment in order to stock the medication for compounding use.

\section{Topical Low-Dose Naltrexone}

Naltrexone $\left(\mathrm{C}_{20} \mathrm{H}_{23} \mathrm{NO}_{4}\right.$, molecular weight $341.4 \mathrm{~kg} / \mathrm{mol}$, pubchem.ncibi.hlm.nih.gov accessed August 1, 2021) is an opioid antagonist that was originally developed as a therapeutic for opioid and alcohol addiction, typically at oral doses from 50 to $100 \mathrm{mg}$ daily. Low-dose naltrexone (typically in doses from 1 to $5 \mathrm{mg}$ daily) has been used for treating bodily neuropathic pain (Younger and Mackey, 2009; Metyas et al., 2018). Ultra-low-dose naltrexone (doses below $1 \mathrm{mg}$ daily) may also be used (Toljan and Vrooman, 2018).

Naltrexone is noted to have effects on opioid receptors (commonly described with mu-opioid receptors as well as others) and non-opioid receptors. A non-opioid receptor that seems to be associated with the functionality of naltrexone as it pertains to pain modulation is the Toll-like receptor, which is found on macrophages and microglia. Microglia are involved in pain through the binding of a protein, high mobility group box 1 , HMGB1) which binds to Toll-like receptors 2 and 4 (Watkins et al., 2007). Toll-like receptor expression has been noted to be upregulated in neuronal injury (Owens et al., 2005). Microglia may then increase the expression of tumor necrosis factor-alpha (TNF-alpha) and other inflammatory mediators via Toll-like receptor as well as NF-KB signaling, indicating a close relationship between inflammation and pain (Nadeau and Rivest, 2000; Thibeault et al., 2001). Ultimately, glial activation is thought to enhance neuroexcitability, which may be associated with the increased perception of pain (Watkins et al., 2007). Naltrexone has been shown to inhibit the IL-6 and TNF-alpha that is produced after Toll-like receptors have interacted with their cognate ligands, which can thereby mitigate pain in animal models (Grace et al., 2015; Cant et al., 2017).

Models of ocular surface injury (penetrating trauma or alkali injury) have been associated with retinal damage and inflammation within the brain by virtue of microglial and macrophage activation (Ferrari et al., 2014; Paschalis et al., 2018). This has suggested that modulation of ocular surface neuropathy can be beneficial in a wide array of conditions. Indeed, oral low-dose naltrexone has been described to be beneficial to patients with a central component of neuropathic ocular pain. Patients treated with oral low-dose naltrexone as monotherapy or as part of a multimodal therapeutic approach was assocated with a decrease in their mean visual analog pain score as well as decrease in their mean quality of life score as assessed by the OPAS (Dieckmann et al., 2021). Topical low-dose naltrexone has been used in a diabetic murine model demonstrating improvements in corneal nerve sensitivity to a filament (von Frey) similar to that used to test human corneal sensation (Cochet-Bonnet enesthesiometer) (Zagon et al., 2014).

Interest in naltrexone's potential to ameliorate corneal neuropathic problems, such as ulcerations and delayed reepithelialization, have led to interest in producing contact lenses that would allow for the ability to deliver a more constant level of low-dose naltrexone to the cornea's sub-basal nerve plexus (Alvarez-Rivera et al., 2019).

Presently Naltrexone, as an eye drop, requires specialty compounding. Naltrexone eye drops are reconstituted from active pharmaceutical ingredient powder because a commercial product does not currently exist. This preparation is considered high-risk compounding because pharmacies start the process with non-sterile powder and sterilize the solution via membrane filtration as the final step. Naltrexone $\mathrm{HCl}$ USP powder is dissolved in sodium chloride $0.9 \%$ sterile injection and preserved with benzalkonium chloride solution (though a preservative-free formulation can be prepared as well). The $\mathrm{pH}$ may range from 4.5 to 6.2 . The solution is drawn up in a luer lock syringe and sterile filtered into droptainers or dispensing devices. For this type of preparation, USP General Chapter 797 allows a Beyond Use Date of 3 days refrigerated or 45 days frozen. Strengths of naltrexone ophthalmic solution range from 0.001 to $0.2 \%$. The compounding of high-risk preparations is performed in an International Organization for Standardization (ISO) 7 ante room and the final filtering and packaging is done in an ISO 5 laminar flow hood.

\section{Topical Enkephalin Modulators: Future Targets}

Because the neuropeptides known as enkephalins can modulate pain, there has been interest in utilizing this pathway as a 
potential pain therapeutic. Enkephalins are associated with an analgesic effect, but their action is relatively short-lived due to the presence of enzymes that rapidly degrade these neuropeptides. Endogenous inhibitors of enkephalin enzymes do exist and are present in foreign body models of ocular pain (Ozdogan et al., 2020; Lasagni Vitar et al., 2021). Thus, pharmacologic inhibition of such enzymes may be a therapeutic target. In one study, the topical administration of PL265, an inhibitor of enkephalinase, in a murine model of corneal pain reduced corneal mechanical and chemical hypersensitivity (Reaux-Le Goazigo et al., 2019). Targeting corneal mu-opioid receptors with agonists may be another therapeutic target as suggested in murine models (Joubert et al., 2020).

\section{DISCUSSION}

There has been substantial progress in the development of tools that can identify corneal neuropathic pain (Qazi et al., 2016; Farhangi et al., 2019). The identification of ocular pain and neuropathic pain features with the OPAS and NPSI questionnaires is an important step forward in better distinguishing patients that are less likely to respond to lubrication like their typical dry eye counterparts. However, significant challenges remain, particularly regarding treatment of corneal neuropathic pain. In vivo confocal microscopy can be helpful in identifying dendritic or other inflammatory cells, which may suggest a role for a brief course of topical corticosteroids. Autologous blood-derived products are a reasonable first-line

\section{REFERENCES}

Aggarwal, S., Colon, C., Kheirkhah, A., and Hamrah, P. (2019). Efficacy of Autologous Serum Tears for Treatment of Neuropathic Corneal Pain. Ocul. Surf. 17 (3), 532-539. doi:10.1016/j.jtos.2019.01.009

Aggarwal, S., Kheirkhah, A., Cavalcanti, B. M., Cruzat, A., Colon, C., Brown, E., et al. (2015). Autologous Serum Tears for Treatment of Photoallodynia in Patients with Corneal Neuropathy: Efficacy and Evaluation with In Vivo Confocal Microscopy. Ocul. Surf. 13 (3), 250-262. doi:10.1016/ j.jtos.2015.01.005

Alio, J. L., Rodriguez, A. E., De Arriba, P., Gisbert, S., and Abdelghany, A. A. (2018). Treatment with Platelet-Rich Plasma of Surgically Related Dormant Corneal Ulcers. Eur. J. Ophthalmol. 28 (5), 515-520. doi:10.1177/ 1120672117747042

Alvarez-Rivera, F., Serro, A. P., Silva, D., Concheiro, A., and Alvarez-Lorenzo, C. (2019). Hydrogels for Diabetic Eyes: Naltrexone Loading, Release Profiles and Cornea Penetration. Mater. Sci. Eng. C Mater. Biol. Appl. 105, 110092. doi:10.1016/j.msec.2019.110092

Asbell, P. A. (2006). Increasing Importance of Dry Eye Syndrome and the Ideal Artificial Tear: Consensus Views from a Roundtable Discussion. Curr. Med. Res. Opin. 22 (11), 2149-2157. doi:10.1185/030079906X132640

Belmonte, C., and Gallar, J. (2011). Cold Thermoreceptors, Unexpected Players in Tear Production and Ocular Dryness Sensations. Invest. Ophthalmol. Vis. Sci. 52 (6), 3888-3892. doi:10.1167/iovs.09-5119

Bouhassira, D., Attal, N., Fermanian, J., Alchaar, H., Gautron, M., Masquelier, E., et al. (2004). Development and Validation of the Neuropathic Pain Symptom Inventory. Pain. 108 (3), 248-257. doi:10.1016/j.pain.2003.12.024

Campos, E., Versura, P., Buzzi, M., Fontana, L., Giannaccare, G., Pellegrini, M., et al. (2020). Blood Derived Treatment from Two Allogeneic Sources for Severe Dry Eye Associated to Keratopathy: a Multicentre Randomised Cross over approach given their association with improvement in comfort and features of neuropathy on in vivo confocal. If there is a significant peripheral component, consideration can be made for other topical therapies such as lacosamide or low-dose naltrexone drops compounded through a specialty pharmacy. While longitudinal comparative studies demonstrating the most effective topical treatment strategies have yet to be performed, it is reassuring that a variety of topical therapeutic options exist for patients with a peripheral component of corneal neuropathic pain and discomfort. A concerted effort on the part of both ophthalmologists and patients offer the possibility of future randomized controlled trials that can provide high-quality evidence for managing corneal neuropathic pain.

\section{AUTHOR CONTRIBUTIONS}

The authors confirm contribution to the paper as follows: study conception and design: JN, DS, GS, and JG; data collection: JN, DS, GS, and JG; analysis and interpretation of results: JN, DS, GS, and JG; draft manuscript preparation: JN, DS, GS, and JG. All authors reviewed the results and approved the final version of the manuscript.

\section{FUNDING}

This work was supported in part by an unrestricted grant from Research to Prevent Blindness.

Clinical Trial. Br. J. Ophthalmol. 104 (8), 1142-1147. doi:10.1136/ bjophthalmol-2019-314859

Cant, R., Dalgleish, A. G., and Allen, R. L. (2017). Naltrexone Inhibits IL-6 and TNFa Production in Human Immune Cell Subsets Following Stimulation with Ligands for Intracellular Toll-like Receptors. Front. Immunol. 8, 809. doi:10.3389/fimmu.2017.00809

Chen, D., Zhang, S., Bian, A., Hong, J., Deng, Y., Zhang, M., et al. (2019). Efficacy and Safety of $0.05 \%$ Cyclosporine Ophthalmic Emulsion in Treatment of Chinese Patients with Moderate to Severe Dry Eye Disease: A 12-Week, Multicenter, Randomized, Double-Masked, Placebo-Controlled Phase III Clinical Study. Medicine (Baltimore). 98 (31), e16710. doi:10.1097/ MD.0000000000016710

Cho, J., Bell, N., Botzet, G., Vora, P., Fowler, B. J., Donahue, R., et al. (2019). Latent Sensitization in a Mouse Model of Ocular Neuropathic Pain. Transl Vis. Sci. Technol. 8 (2), 6. doi:10.1167/tvst.8.2.6

Craig, J. P., Nichols, K. K., Akpek, E. K., Caffery, B., Dua, H. S., Joo, C. K., et al. (2017). Tfos Dews Ii Definition and Classification Report. Ocul. Surf. 15 (3), 276-283. doi:10.1016/j.jtos.2017.05.008

Dieckmann, G., Goyal, S., and Hamrah, P. (2017). Neuropathic Corneal Pain: Approaches for Management. Ophthalmology. 124 (11s), S34-s47. doi:10.1016/ j.ophtha.2017.08.004

Dieckmann, G., Ozmen, M. C., Cox, S. M., Engert, R. C., and Hamrah, P. (2021). Low-Dose Naltrexone Is Effective and Well-Tolerated for Modulating Symptoms in Patients With Neuropathic Corneal Pain. Ocul. Surf. 20, 33-38. doi:10.1016/j.jtos.2020.12.003

Errington, A. C., Stöhr, T., Heers, C., and Lees, G. (2008). The Investigational Anticonvulsant Lacosamide Selectively Enhances Slow Inactivation of VoltageGated Sodium Channels. Mol. Pharmacol. 73 (1), 157-169. doi:10.1124/ mol.107.039867

Farhangi, M., Feuer, W., Galor, A., Bouhassira, D., Levitt, R. C., Sarantopoulos, C. D., et al. (2019). Modification of the Neuropathic Pain Symptom Inventory for 
Use in Eye Pain (NPSI-Eye). Pain. 160 (7), 1541-1550. doi:10.1097/ j.pain. 0000000000001552

Ferrari, G., Bignami, F., Giacomini, C., Capitolo, E., Comi, G., Chaabane, L., et al. (2014). Ocular Surface Injury Induces Inflammation in the Brain: In Vivo and Ex Vivo Evidence of a Corneal-Trigeminal Axis. Invest. Ophthalmol. Vis. Sci. 55 (10), 6289-6300. doi:10.1167/iovs.14-13984

Galor, A., Batawi, H., and Felix, E. R. (2015a). Incomplete Response to Artificial Tears Is Associated with Features of Neuropathic Ocular Pain. $\mathrm{Br}$. J. Ophthalmol. 99 (5), 665-668. doi:10.1136/bjophthalmol-2015-307094

Galor, A., Zlotcavitch, L., Walter, S. D., Felix, E. R., Feuer, W., Martin, E. R., et al. (2015b). Dry Eye Symptom Severity and Persistence Are Associated with Symptoms of Neuropathic Pain. Br. J. Ophthalmol. 99, 665-668. doi:10.1136/bjophthalmol-2014-306057

Galor, A., Batawi, H., Felix, E. R., Margolis, T. P., Sarantopoulos, K. D., Martin, E. R., et al. (2016). Incomplete Response to Artificial Tears Is Associated with Features of Neuropathic Ocular Pain. Br. J. Ophthalmol. 100 (6), 745-749. doi:10.1136/bjophthalmol-2015-307094

Gandhi, N. B., Su, Z., Zhang, X., Volpe, E. A., Pelegrino, F. S., Rahman, S. A., et al. (2013). Dendritic Cell-Derived Thrombospondin-1 Is Critical for the Generation of the Ocular Surface Th17 Response to Desiccating Stress. J. Leukoc. Biol. 94 (6), 1293-1301. doi:10.1189/jlb.1012524

Geerling, G., Daniels, J. T., Dart, J. K., Cree, I. A., and Khaw, P. T. (2001). Toxicity of Natural Tear Substitutes in a Fully Defined Culture Model of Human Corneal Epithelial Cells. Invest. Ophthalmol. Vis. Sci. 42 (5), 948-956. doi:10.1016/ s0002-9394(01)01230-2

Giannaccare, G., Buzzi, M., Fresina, M., Velati, C., and Versura, P. (2017). Efficacy of 2-Month Treatment With Cord Blood Serum Eye Drops in Ocular Surface Disease: An In Vivo Confocal Microscopy Study. Cornea. 36 (8), 915-921. doi:10.1097/ICO.0000000000001257

Gipson, I. K., Spurr-Michaud, S., Argüeso, P., Tisdale, A., Ng, T. F., and Russo, C. L. (2003). Mucin Gene Expression in Immortalized Human Corneal-Limbal and Conjunctival Epithelial Cell Lines. Invest. Ophthalmol. Vis. Sci. 44 (6), 2496-2506. doi:10.1167/iovs.02-0851

Grace, P. M., Shimizu, K., Strand, K. A., Rice, K. C., Deng, G., Watkins, L. R., et al. (2015). (+)-Naltrexone Is Neuroprotective and Promotes Alternative Activation in the Mouse hippocampus After Cardiac Arrest/ Cardiopulmonary Resuscitation. Brain Behav. Immun. 48, 115-122. doi:10.1016/j.bbi.2015.03.005

Hamrah, P., Huq, S. O., Liu, Y., Zhang, Q., and Dana, M. R. (2003). Corneal Immunity Is Mediated by Heterogeneous Population of Antigen-Presenting Cells. J. Leukoc. Biol. 74 (2), 172-178. doi:10.1189/jlb.1102544

Joubert, F., Guerrero-Moreno, A., Fakih, D., Reboussin, E., Gaveriaux-Ruff, C., Acosta, M. C., et al. (2020). Topical Treatment with a Mu Opioid Receptor Agonist Alleviates Corneal Allodynia and Corneal Nerve Sensitization in Mice. Biomed. Pharmacother. 132, 110794. doi:10.1016/j.biopha.2020.110794

Khamar, P., Nair, A. P., Shetty, R., Vaidya, T., Subramani, M., Ponnalagu, M., et al. (2019). Dysregulated Tear Fluid Nociception-Associated Factors, Corneal Dendritic Cell Density, and Vitamin D Levels in Evaporative Dry Eye. Invest. Ophthalmol. Vis. Sci. 60 (7), 2532-2542. doi:10.1167/iovs.19-26914

Kheirkhah, A., Rahimi Darabad, R., Cruzat, A., Hajrasouliha, A. R., Witkin, D., Wong, N., et al. (2015). Corneal Epithelial Immune Dendritic Cell Alterations in Subtypes of Dry Eye Disease: A Pilot In Vivo Confocal Microscopic Study. Invest. Ophthalmol. Vis. Sci. 56 (12), 7179-7185. doi:10.1167/iovs.15-17433

Klitsch, A., Evdokimov, D., Frank, J., Thomas, D., Saffer, N., Meyer Zu Altenschildesche, C., et al. (2020). Reduced Association Between Dendritic Cells and Corneal Sub-basal Nerve Fibers in Patients with Fibromyalgia Syndrome. J. Peripher. Nerv Syst. 25 (1), 9-18. doi:10.1111/jns.12360

Kovács, I., Dienes, L., Perényi, K., Quirce, S., Luna, C., Mizerska, K., et al. (2016). Lacosamide Diminishes Dryness-Induced Hyperexcitability of Corneal Cold Sensitive Nerve Terminals. Eur. J. Pharmacol. 787, 2-8. doi:10.1016/ j.ejphar.2016.05.044

Lasagni Vitar, R. M., Barbariga, M., Fonteyne, P., Bignami, F., Rama, P., and Ferrari, G. (2021). Modulating Ocular Surface Pain Through Neurokinin-1 Receptor Blockade. Invest. Ophthalmol. Vis. Sci. 62 (3), 26. doi:10.1167/ iovs.62.3.26

Mahelkova, G., Jirsova, K., Seidler Stangova, P., Palos, M., Vesela, V., Fales, I., et al. (2017). Using Corneal Confocal Microscopy to Track Changes in the Corneal
Layers of Dry Eye Patients after Autologous Serum Treatment. Clin. Exp. Optom. 100 (3), 243-249. doi:10.1111/cxo.12455

Mehra, D., Cohen, N. K., and Galor, A. (2020). Ocular Surface Pain: A Narrative Review. Ophthalmol. Ther. 9 (3), 1-21. doi:10.1007/s40123-020-00263-9

Metyas, S., Chen, C. L., Yeter, K., Solyman, J., and Arkfeld, D. G. (2018). Low Dose Naltrexone in the Treatment of Fibromyalgia. Curr. Rheumatol. Rev. 14 (2), 177-180. doi:10.2174/1573397113666170321120329

Mondy, P., Brama, T., Fisher, J., Gemelli, C. N., Chee, K., Keegan, A., et al. (2015). Sustained Benefits of Autologous Serum Eye Drops on Self-Reported Ocular Symptoms and Vision-Related Quality of Life in Australian Patients with Dry Eye and Corneal Epithelial Defects. Transfus. Apher. Sci. 53 (3), 404-411. doi:10.1016/j.transci.2015.11.011

Nadeau, S., and Rivest, S. (2000). Role of Microglial-Derived Tumor Necrosis Factor in Mediating CD14 Transcription and Nuclear Factor Kappa B Activity in the Brain during Endotoxemia. J. Neurosci. 20 (9), 3456-3468. doi:10.1523/ jneurosci.20-09-03456.2000

Nicolle, P., Liang, H., Reboussin, E., Rabut, G., Warcoin, E., Brignole-Baudouin, F., et al. (2018). Proinflammatory Markers, Chemokines, and Enkephalin in Patients Suffering from Dry Eye Disease. Int. J. Mol. Sci. 19 (4), 1221. doi:10.3390/ijms19041221

Niespodziany, I., Leclère, N., Vandenplas, C., Foerch, P., and Wolff, C. (2013). Comparative Study of Lacosamide and Classical Sodium Channel Blocking Antiepileptic Drugs on Sodium Channel Slow Inactivation. J. Neurosci. Res. 91 (3), 436-443. doi:10.1002/jnr.23136

Owens, T., Babcock, A. A., Millward, J. M., and Toft-Hansen, H. (2005). Cytokine and Chemokine Inter-Regulation in the Inflamed or Injured CNS. Brain Res. Brain Res. Rev. 48 (2), 178-184. doi:10.1016/j.brainresrev.2004.12.007

Ozdogan, S., Sonmez, C., Yolcu, D., and Gungormus, M. (2020). Tear Opiorphin Levels in Ocular Pain Caused by Corneal Foreign Body. Cornea. 39 (11), 1377-1380. doi:10.1097/ICO.0000000000002383

Ozen, S., Ozer, M. A., and Akdemir, M. O. (2017). Vitamin B12 Deficiency Evaluation and Treatment in Severe Dry Eye Disease with Neuropathic Ocular Pain. Graefes Arch. Clin. Exp. Ophthalmol. 255 (6), 1173-1177. doi:10.1007/ s00417-017-3632-y

Pan, Q., Angelina, A., Marrone, M., Stark, W. J., and Akpek, E. K. (2017). Autologous Serum Eye Drops for Dry Eye. Cochrane Database Syst. Rev. 2 (2), Cd009327. doi:10.1002/14651858.CD009327.pub3

Paschalis, E. I., Lei, F., Zhou, C., Kapoulea, V., Thanos, A., Dana, R., et al. (2018). The Role of Microglia and Peripheral Monocytes in Retinal Damage After Corneal Chemical Injury. Am. J. Pathol. 188 (7), 1580-1596. doi:10.1016/ j.ajpath.2018.03.005

Phan, T. M., Foster, C. S., Boruchoff, S. A., Zagachin, L. M., and Colvin, R. B. (1987). Topical Fibronectin in the Treatment of Persistent Corneal Epithelial Defects and Trophic Ulcers. Am. J. Ophthalmol. 104 (5), 494-501. doi:10.1016/ s0002-9394(14)74107-8

Qazi, Y., Hurwitz, S., Khan, S., Jurkunas, U. V., Dana, R., and Hamrah, P. (2016). Validity and Reliability of a Novel Ocular Pain Assessment Survey (OPAS) in Quantifying and Monitoring Corneal and Ocular Surface Pain. Ophthalmology. 123 (7), 1458-1468. doi:10.1016/j.ophtha.2016.03.006

Reaux-Le Goazigo, A., Poras, H., Ben-Dhaou, C., Ouimet, T., Baudouin, C., Wurm, M., et al. (2019). Dual Enkephalinase Inhibitor PL265: a Novel Topical Treatment to Alleviate Corneal Pain and Inflammation. Pain. 160 (2), 307-321. doi:10.1097/j.pain.0000000000001419

Ripa, M., Jabbehdari, S., Yazdanpanah, G., Lukacs, E., Karcher, B., Iqbal, O., et al. (2020). The Role of Multisystem Disease in Composition of Autologous Serum Tears and Ocular Surface Symptom Improvement. Ocul. Surf. 18 (3), 499-504. doi:10.1016/j.jtos.2020.02.011

Rogawski, M. A., Tofighy, A., White, H. S., Matagne, A., and Wolff, C. (2015). Current Understanding of the Mechanism of Action of the Antiepileptic Drug Lacosamide. Epilepsy Res. 110, 189-205. doi:10.1016/j.eplepsyres.2014.11.021

Rosenthal, P., Baran, I., and Jacobs, D. S. (2009). Corneal Pain without Stain: Is it Real? Ocul. Surf. 7 (1), 28-40. doi:10.1016/s1542-0124(12)70290-2

Rosenthal, P., and Borsook, D. (2012). The Corneal Pain System. Part I: the Missing Piece of the Dry Eye Puzzle. Ocul. Surf. 10 (1), 2-14. doi:10.1016/ j.jtos.2012.01.002

Shetty, R., Deshpande, K., Deshmukh, R., Jayadev, C., and Shroff, R. (2016a). Bowman Break and Subbasal Nerve Plexus Changes in a Patient With Dry Eye 
Presenting With Chronic Ocular Pain and Vitamin D Deficiency. Cornea. 35 (5), 688-691. doi:10.1097/ICO.0000000000000785

Shetty, R., Sethu, S., Deshmukh, R., Deshpande, K., Ghosh, A., Agrawal, A., et al. (2016b). Corneal Dendritic Cell Density Is Associated with Subbasal Nerve Plexus Features, Ocular Surface Disease Index, and Serum Vitamin D in Evaporative Dry Eye Disease. Biomed. Res. Int. 2016, 4369750. doi:10.1155/ 2016/4369750

Siedlecki, A. N., Smith, S. D., Siedlecki, A. R., Hayek, S. M., and Sayegh, R. R. (2020). Ocular Pain Response to Treatment in Dry Eye Patients. Ocul. Surf. 18 (2), 305-311. doi:10.1016/j.jtos.2019.12.004

Thibeault, I., Laflamme, N., and Rivest, S. (2001). Regulation of the Gene Encoding the Monocyte Chemoattractant Protein 1 (MCP-1) in the Mouse and Rat Brain in Response to Circulating LPS and Proinflammatory Cytokines. J. Comp. Neurol. 434 (4), 461-477. doi:10.1002/cne.1187

Toljan, K., and Vrooman, B. (2018). Low-Dose Naltrexone (LDN)-Review of Therapeutic Utilization. Med. Sci. (Basel). 6 (4), 82. doi:10.3390/medsci6040082

Tsubota, K., Goto, E., Fujita, H., Ono, M., Inoue, H., Saito, I., et al. (1999a). Treatment of Dry Eye by Autologous Serum Application in Sjögren's Syndrome. Br. J. Ophthalmol. 83 (4), 390-395. doi:10.1136/bjo.83.4.390

Tsubota, K., Goto, E., Shimmura, S., and Shimazaki, J. (1999b). Treatment of Persistent Corneal Epithelial Defect by Autologous Serum Application. Ophthalmology. 106 (10), 1984-1989. doi:10.1016/S0161-6420(99)90412-8

Villani, E., Garoli, E., Termine, V., Pichi, F., Ratiglia, R., and Nucci, P. (2015). Corneal Confocal Microscopy in Dry Eye Treated with Corticosteroids. Optom. Vis. Sciofficial Publication Am. Acad. Optom. 92 (9), e290-5. doi:10.1097/ OPX.0000000000000600

Wang, M., Yennam, S., and McMillin, J. (2021). Combined Therapy of Ocular Surface Disease with Plasma Rich in Growth Factors and Scleral Contact Lenses. Ocul. Surf., S1542-0124(21)00102-6. doi:10.1016/j.jtos.2021.09.003

Wang, X., Yu, Y., Ma, R., Shao, N., and Meng, H. (2018). Lacosamide Modulates Collapsin Response Mediator Protein 2 and Inhibits Mossy Fiber Sprouting after Kainic Acid-Induced Status Epilepticus. Neuroreport. 29 (16), 1384-1390. doi:10.1097/WNR.0000000000001123

Watkins, L. R., Hutchinson, M. R., Ledeboer, A., Wieseler-Frank, J., Milligan, E. D., and Maier, S. F. (2007). Norman Cousins Lecture. Glia as the "bad Guys": Implications for Improving Clinical Pain Control and the Clinical Utility of Opioids. Brain Behav. Immun. 21 (2), 131-146. doi:10.1016/j.bbi.2006.10.011

White, C. J., Thomas, C. R., and Byrne, M. E. (2014). Bringing comfort to the Masses: a Novel Evaluation of comfort Agent Solution Properties. Cont Lens Anterior Eye. 37 (2), 81-91. doi:10.1016/j.clae.2013.07.004
Wilson, S. M., and Khanna, R. (2015). Specific Binding of Lacosamide to Collapsin Response Mediator Protein 2 (CRMP2) and Direct Impairment of its Canonical Function: Implications for the Therapeutic Potential of Lacosamide. Mol. Neurobiol. 51 (2), 599-609. doi:10.1007/s12035-014-8775-9

Wu, Y., Jin, X., Mou, Y., Yuan, K., Min, J., and Huang, X. (2021). A 4-week, Randomized, Double-Masked Study to Evaluate Efficacy of Deproteinized Calf Blood Extract Eye Drops versus Sodium Hyaluronate 0.3\% Eye Drops in Dry Eye Patients with Ocular Pain. Ann. Palliat. Med. 10 (4), 3617-3625. doi:10.21037/apm-20-1453

Younger, J., and Mackey, S. (2009). Fibromyalgia Symptoms Are Reduced by LowDose Naltrexone: a Pilot Study. Pain Med. 10 (4), 663-672. doi:10.1111/j.15264637.2009.00613.x

Zagon, I. S., Sassani, J. W., Immonen, J. A., and McLaughlin, P. J. (2014). Ocular Surface Abnormalities Related to Type 2 Diabetes Are Reversed by the Opioid Antagonist Naltrexone. Clin. Exp. Ophthalmol. 42 (2), 159-168. doi:10.1111/ ceo. 12144

Zhang, X., Schaumburg, C. S., Coursey, T. G., Siemasko, K. F., Volpe, E. A., Gandhi, N. B., et al. (2014). CD8 ${ }^{+}$Cells Regulate the T Helper-17 Response in an Experimental Murine Model of Sjögren Syndrome. Mucosal Immunol. 7 (2), 417-427. doi:10.1038/mi.2013.61

Conflict of Interest: DS was employed by A\&O Compounding Pharmacy.

The remaining authors declare that the research was conducted in the absence of any commercial or financial relationships that could be construed as a potential conflict of interest.

Publisher's Note: All claims expressed in this article are solely those of the authors and do not necessarily represent those of their affiliated organizations, or those of the publisher, the editors and the reviewers. Any product that may be evaluated in this article, or claim that may be made by its manufacturer, is not guaranteed or endorsed by the publisher.

Copyright (๑) 2022 Nortey, Smith, Seitzman and Gonzales. This is an open-access article distributed under the terms of the Creative Commons Attribution License (CC $B Y$ ). The use, distribution or reproduction in other forums is permitted, provided the original author(s) and the copyright owner(s) are credited and that the original publication in this journal is cited, in accordance with accepted academic practice. No use, distribution or reproduction is permitted which does not comply with these terms. 